\title{
Viability of Utilizing CFRP Composites for Improving the Structural Behavior of Steel Beams
}

\author{
Khairedin M. Abdalla*, Ghazi Abu-Farsakh, and Montaha Al-Shdiefat \\ Department of Civil Engineering, Jordan University of Science \& Technology, Jordan
}

Received 21 April 2019; Accepted 12 September 2019

\begin{abstract}
This paper presents an experimental investigation to evaluate the viability of utilizing carbon fiber reinforced polymer (CFRP) composites for strengthening of indeterminate steel beams. Ten steel I-beams were strengthened using unidirectional CFRP composites in a form of plates attached on the flanges and/or web. The beams were tested as fixedends under a one center load distributed over the piston area. The indeterminate steel beams having two fixed ends required high load to cause failure. Although, the maximum load carrying capacities were not significantly improved due to debonding of the CFRP plates, but the strengthened-beams demonstrated reasonable improvement in the flexural-stiffness and slight increase in the torsional-stiffness. In most cases, the governing buckling-mode for the strengthened and unstrengthened beams was inelastic lateral-torsional buckling combined with local flange- buckling. The findings of this study show encouraging enhancement in the structural behavior of intermediate steel beams after strengthening with CFRP composites. This study provides an important guidance for future research toward development of means to realize the full potential use of CFRP composites for strengthening of steel beams.
\end{abstract}

Keywords: Strengthening, CFRP composites, indeterminate steel beams, flexural stiffness

\section{Introduction}

Structural steel and reinforced concrete structures are employed in construction daily all over the world, and the infrastructure and construction are ever proliferating and developing. Large number of structures becomes unsafe to use or deteriorates on a daily basis owing to changes in design configurations, loading, the use of low-quality building materials, and/or due to natural events like earthquakes. It is more economical to repair and retrofit the deteriorating components than replacing the entire structure. Moreover, in certain cases as in bridges, the process of strengthening and rehabilitation take less time and reduce the possibility of service interruption. The rehabilitation and strengthening processes were traditionally performed through attachment of steel plates, but this process is recently achieved by the use of CFRP composites if a form of sheets, strips, or plates [1- 7].

Over the past few years, the material strength and stiffness characteristics of the CFRP sheets improved greatly [8]. Recently, some types of CFRP composites have almost double elastic modulus of structural mild-steel (Figure 1). Also, the advantages of corrosion resistance and light weight of CFRP composites over steel in highly corrosive environments make them more effective such as in off-shore structures [9]. In-service characteristics of the CFRP composites made them a good choice for rehabilitation of damaged bridge box girders, because of their excellent fatigue and strength properties. Their high

*E-mail address: abdalla@just.edu.jo

ISSN: $1791-2377$ @ 2019 School of Science, IHU. All rights reserved.

doi:10.25103/jestr.124.07 strength-to-density ratio made them excellent choice for retrofitting/strengthening of steel beams and structures [10]. Variations of the mechanical characteristics of CFRP composites and their effect on the strengthened systems under various environmental and loading conditions were studied [11]. The authors studied retrofitting and strengthening of double-strap joints of corroded steel plates under tension and also, they investigated the flexural performance of deteriorated steel I-beams using externally bonded CFRP composite plates [11]. The strengthened beams with CFRP plates experienced limited ductility upon failure; either by debonding or rupture, at higher load capacities than those of the unstrengthened beams [12].

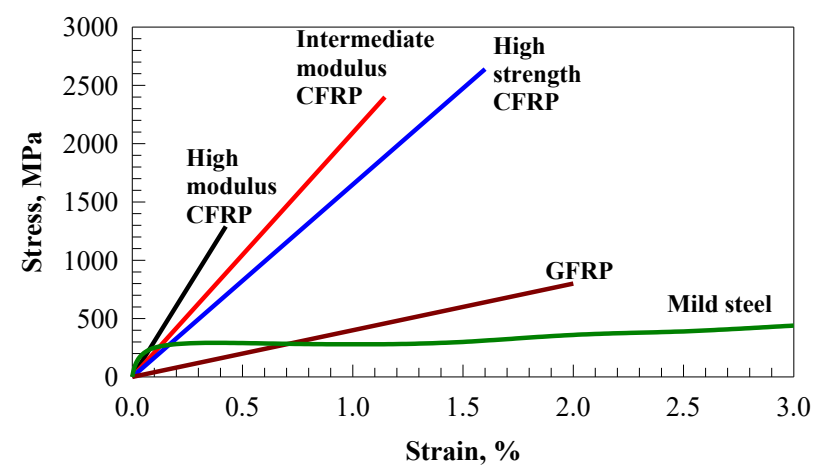

Fig. 1 Comparison of stress-strain relations of mild steel, CFRP, and GFRP composites [9]

Narmashiri et al. [12, 13] evaluated the load-carrying capacities of strengthened steel I-beams, which increased with increased length and thickness of the CFRP plates. The use of short CFRP plates led to premature end-debonding, 
Khairedin M. Abdalla, Ghazi Abu-Farsakh, and Montaha Al-Shdiefat/

Journal of Engineering Science and Technology Review 12 (4) (2019) 60 - 68

while using long plates raised the resistance against the enddebonding. Also, they carried out an experimental testing on flexural-strengthening of steel I-beams using CFRP strips, which showed an improved flexural behavior. Galal et al. [14] investigated the effectiveness of using CFRP composites in retrofitting of deteriorated steel beams, and proposed an anchorage system to enhance the ductile strength of the deteriorated beams to remove early peel-off from the CFRP sheets.

Dawood et al. [15] found that the use of reverse-tapered joint configuration may improve the joint-capacity. Such findings indicate that steel beams can be strengthened using CFRP laminates, both in shear and in flexure. They concluded that shear strength improvement of nearly 25 to $39 \%$ can be readily achieved by attaching CFRP strips to webs of steel beams [16]. Peiris [17] conducted experimental and analytical investigations on bond characteristics and flexural-behavior of steel members strengthened with ultra-high and normal modulus CFRP laminates. In both cases, failure occurred at the interface of laminate edges followed by progressive debonding initiated at laminate-edge towards its center. Few studies investigated the use of pre-stressed CFRP laminates to strengthen steel structures. It was noticed that the use of CFRP composites for retrofitting steel structures is not very popular $[18,19]$.

Strengthening of notched steel beams using CFRP plates was found to double its strength, while the brittle fracture caused by intermediate debonding initiated from the notch location limits the ductility enhancement of the retrofitted beams [20]. Alternatively, notched steel beams strengthened with pre-stressed CFRP plates with end-anchorage systems showed a delayed debonding propagation of the strengthened beams, preventing premature failure [21]. Mohammed et al. [22] studied the effectiveness of CFRP composites to recover strength and stiffness of steel beams having web-openings. The load carrying capacity of beams achieved an increase over the un-altered beams from 5 to $20 \%$. A parametric study carried out by Omar et al. [23] revealed that CFRP sheets were very efficient in reinforcing compact mono-symmetric sections, whereas the effect on non-compact sections was very small. The bonded CFRP sheets allowed for reaching the ultimate strength of steel beams provided that enough bond-length was ensured [23].

\section{Experimental Setup}

\section{a) Details of the tested beams}

Ten indeterminate steel I-beams were tested under one-point center load (Figure 2) that was distributed over the piston area (about $50 \mathrm{~mm} \times 300 \mathrm{~mm}$ ). The span length was $1530 \mathrm{~mm}$ and the ends were both fixed. Table 1 provides description of the ten steel beams. Two specimens were tested as reference without strengthening, one without stiffeners and one with stiffeners; designated as B0RN and B1RNS, respectively. Two specimens strengthened with CFRP plates attached to the flanges in the middle without and with stiffeners; designated as B2NCF and B7SCF, respectively. Two specimens strengthened with CFRP plates in the web in the middle of the beam without and with stiffeners; designated as B $3 \mathrm{NCW}$ and B8SCW, respectively. Two specimens strengthened with CFRP plates in the web and flanges in the middle of the beam without and with stiffeners; designated as B4NCFW and B9SCFW, respectively. Lastly, two specimens strengthened with CFRP plates in the flanges and web at a distance of 38 $\mathrm{cm}$ from the support on both sides without and with stiffeners; designated as B5NCFW38 and B10SCFW38, respectively.

The used CFRP composite is factory-pultruded plate consists of unidirectional, stretched carbon fibers in epoxy resin matrix. Strain gages were used for measurements of the CFRP and steel strains. All CFRP plates have a length of 300 $\mathrm{mm}$ and two widths, 1) Four CFRP plates of $50 \mathrm{~mm}$-width attached at the center of the web on both sides, and 2) Four CFRP plates of $10 \mathrm{~mm}$-width attached at the inner-sides of the top and bottom flanges.

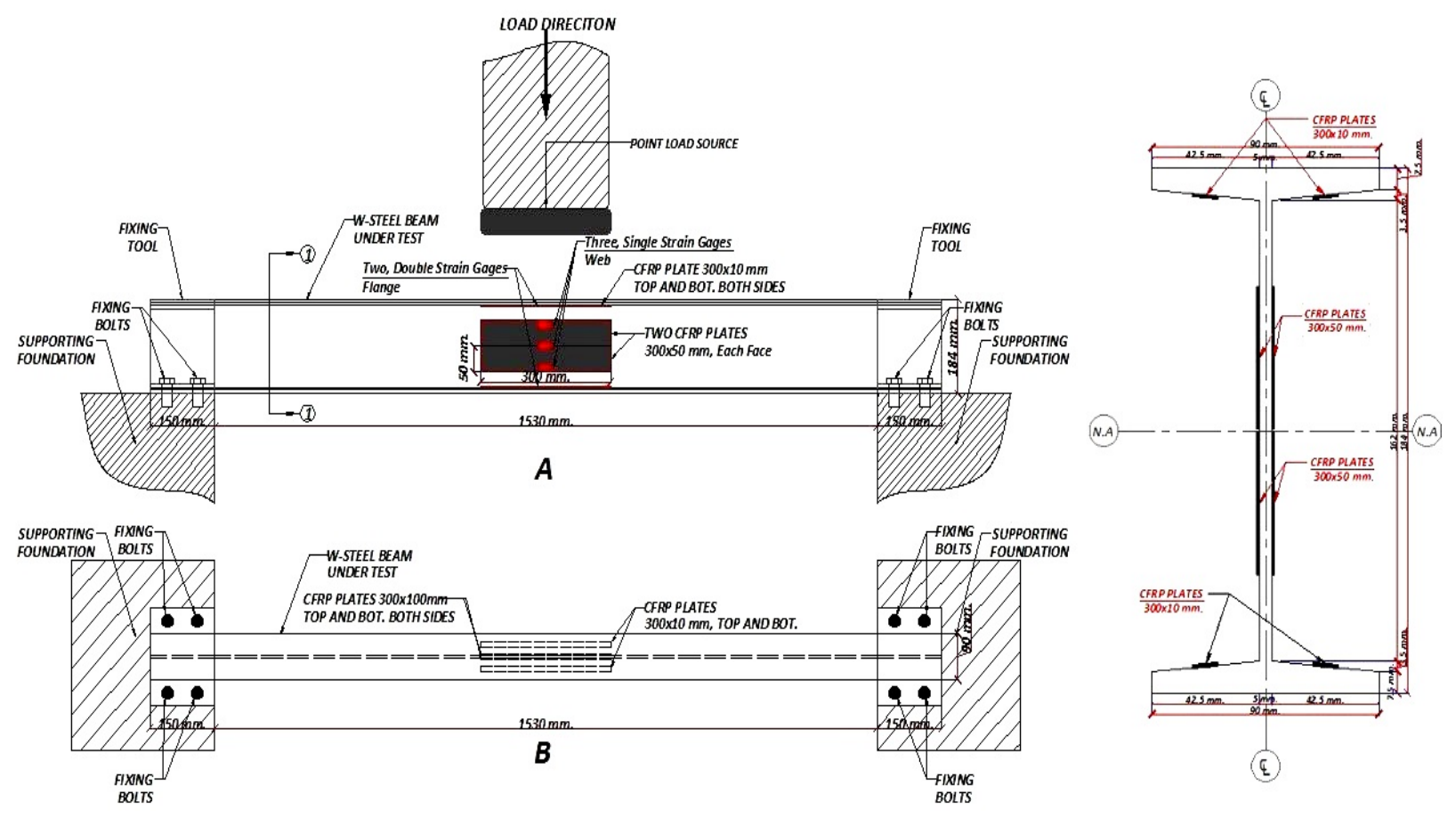


Khairedin M. Abdalla, Ghazi Abu-Farsakh, and Montaha Al-Shdiefat/

Journal of Engineering Science and Technology Review 12 (4) (2019) 60 - 68

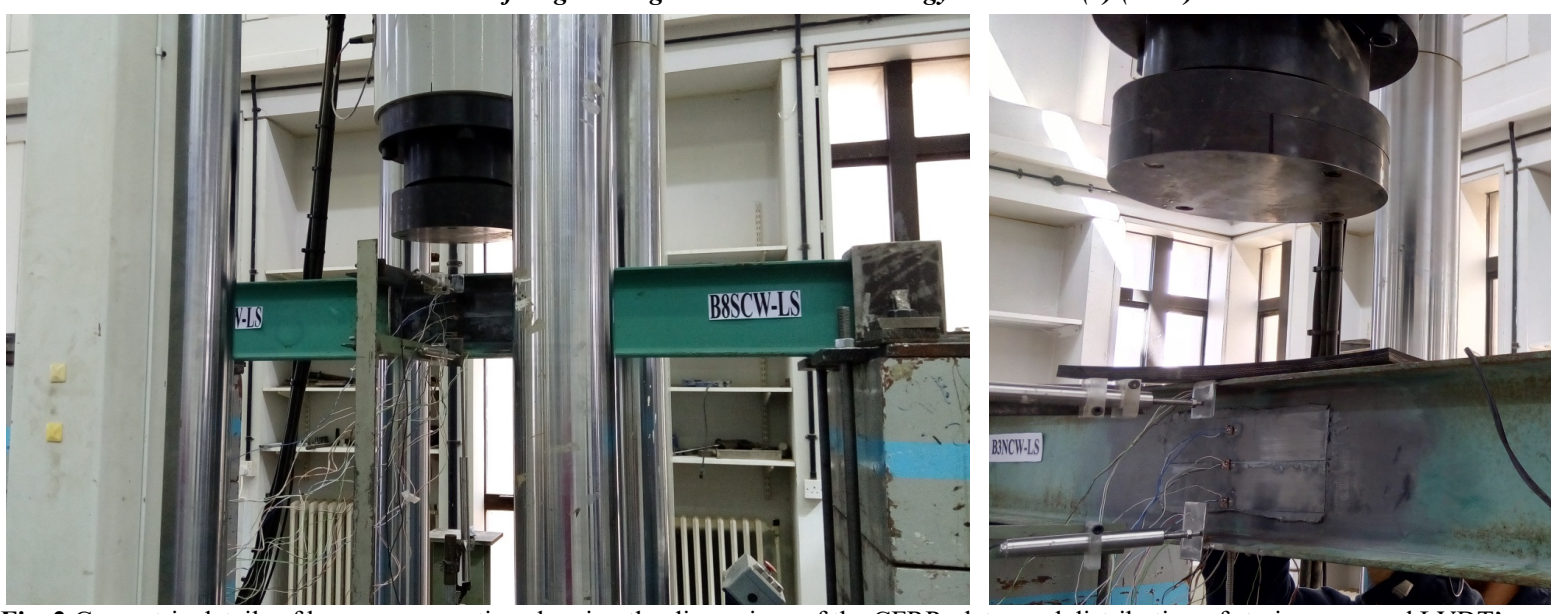

Fig. 2 Geometric details of beam cross-section showing the dimensions of the CFRP-plates and distribution of strain gages and LVDT's.

Table 1. Designation of the Tested Beams Based on the Parameters

\begin{tabular}{l|l}
\hline Sample & Description of steel beam \\
\hline B0RN & Beam 0: Reference beam with no stiffeners and without CFRP. \\
B1RS & Beam 1: Reference beam with stiffeners and without CFRP. \\
B2NCF & Beam 2: Steel beam with no stiffeners and with CFRP in flange in the middle of the beam. \\
B3NCW & Beam 3: Steel beam with no stiffeners and with CFRP in web in the middle of the beam. \\
B4NCFW & Beam 4: Steel beam with no stiffeners and with CFRP in web and flange in the middle of the beam. \\
B5NCFW38 & Beam 5: Steel beam with no stiffeners and with CFRP in flange and web at a distance of $38 \mathrm{~cm}$ from \\
B7SCF & Beace of support on the two web-faces at both ends. \\
B8SCW & Beam 8: Steel beam with stiffeners and CFRP in flange in the middle of the beam. \\
B9SCFW & Beam 9: Steel beam with stiffeners and CFRP in flange and web at the middle of the beam. \\
B10SCFW38 & Beam 10: Steel beam with stiffeners and with CFRP in flange and web at a distance of $38 \mathrm{~cm} \mathrm{from}$ \\
& the face of support on the two web-faces at both ends. \\
\hline
\end{tabular}
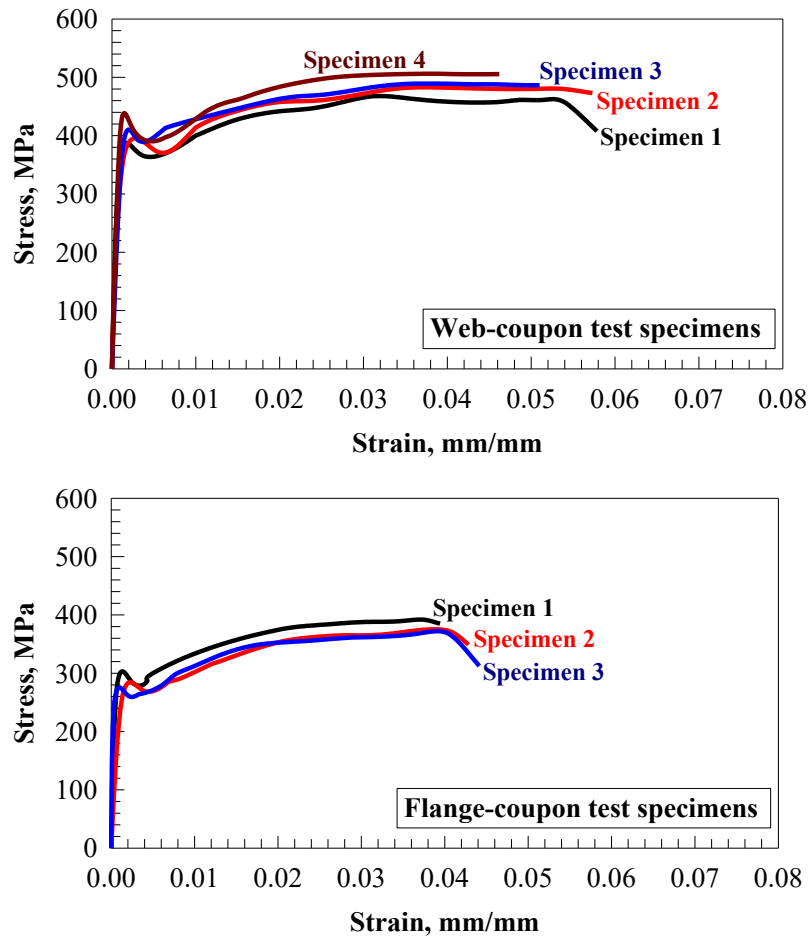

Fig. 3 Stress-strain curves for the coupon test specimens

\section{b) Steel stress-strain relations}

In order to determine the tensile mechanical properties of the steel beams, four coupon web-specimens and three coupon flange-specimens were tested in axial tension tests. The stress-strain curves for flange and web specimens of the beams are shown in Figure 3. All tests were carried out using
$1200 \mathrm{kN}$ Dartec testing machine at the Structural Laboratory of Civil Engineering Department at Jordan University of Science and Technology.

\section{Experimental Results and Discussion}

\section{a) Mid Span Deflections}

A comparison of the central mid-span deflections between the different beams without stiffeners is shown in Figure 4. The results showed strength-variation ranging between $165 \mathrm{kN}$ to $180 \mathrm{kN}$. The highest strength was recorded for the reference beam $(\mathrm{B} 0 \mathrm{RN})$, which indicates that there is no improvement in the beam strength after using CFRP plates. This may be attributed to the pre-mature debonding of the CFRP plates for the strengthened specimens at loads lower than the reference beam (B0RN). Consecutive debonding of the CFRP plates was observed; the first incidence of debonding occurred at a load of $40 \mathrm{kN}$. As shown in Figure 4, B5NCFW38 exhibited the maximum deflection of $35 \mathrm{~mm}$, which indicates that the CFRP plates improve the beam stiffness significantly. The yielding loads were approximately comparable. The recorded yielding loads for B4NCFW and B5NCFW38 were $143.5 \mathrm{kN}$ and $144.5 \mathrm{kN}$, respectively. The lowest and highest yielding loads of $130.2 \mathrm{kN}$ and $160.2 \mathrm{kN}$ occurred in B3NCW and $\mathrm{B} 0 \mathrm{RN}$, respectively. The maximum deflections arranged in an ascending order along with the corresponding maximum loads were: B5NCFW38 (25 mm at $173 \mathrm{kN})$, B4NCFW (27 $\mathrm{mm}$ at $174 \mathrm{kN}), \mathrm{B} 3 \mathrm{NCW}(31 \mathrm{~mm}$ at $165 \mathrm{kN}), \mathrm{B} 2 \mathrm{NCF}$ (44 mm at $174 \mathrm{kN})$ and $\mathrm{B} 0 \mathrm{RN}(55 \mathrm{~mm}$ at $180 \mathrm{kN})$. The reference beam without stiffeners (BORN) exhibited more ductile behavior than the rest of the strengthen beams. 
Khairedin M. Abdalla, Ghazi Abu-Farsakh, and Montaha Al-Shdiefat/

Journal of Engineering Science and Technology Review 12 (4) (2019) 60 - 68
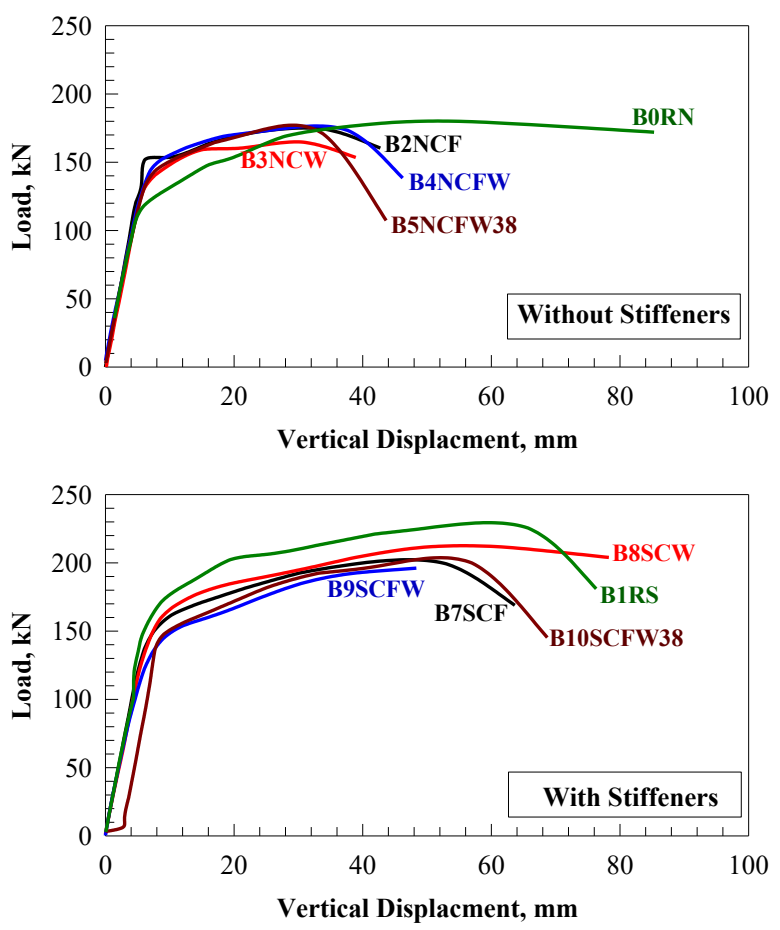

Fig. 4 Load versus mid span deflection of all beams

The results of this group also showed no strength improvement after applying the CFRP plates; the reference beam (B1RS) showed the highest strength. This might be attributed to the distortion of beams resulting from the unsymmetrical behavior of the debonded CFRP plates placed on either side of the beams; the first incidence of debonding occurred at a load of $134.35 \mathrm{kN}$. This indicates that CFRPplates are disadvantageous to indeterminate beams of high strength. The beams unsupported lateral-length $\left(\mathrm{L}_{\mathrm{b}}\right)$ was 1.53 $\mathrm{m}$, which is between the $\mathrm{Lp}$ and $\mathrm{Lr}$ (Table 2) and this drives the steel beam to fail inelastically at smaller moments. Some of the beams were affected and their vertical displacement decreased. Beam B9SFW had the maximum vertical displacement of $50 \mathrm{~mm}$ (Figure 4) indicating that the use of CFRP plates resulted in an improvement in the beam stiffness. The yielding points for some of the beams with stiffeners were close to each other. For instance, the yielding loads for beam B9SFW, B10SCFW38, and B7SCF were $144.7 \mathrm{kN}, 147.7 \mathrm{kN}$, and $150.2 \mathrm{kN}$, respectively. The yielding load was slightly higher for beam B8SCW $(159.0 \mathrm{kN})$. The highest yielding load of $170.7 \mathrm{kN}$ was recorded for beam B1RS. As shown in Figure 4, the mid span deflections increased in an ascending order as: B7SCF (40 mm at $200 \mathrm{kN}$ ), B9SFW (47 mm at $196 \mathrm{kN}$ ), B1RS $(53 \mathrm{~mm}$ at $228 \mathrm{kN}), \mathrm{B} 10 \mathrm{SCFW} 38(58 \mathrm{~mm}$ at $200 \mathrm{kN})$, and B8SCW $(62 \mathrm{~mm}$ at $212 \mathrm{kN})$. The maximum load carrying capacity of $228 \mathrm{kN}$ was for the reference beam (B1RS), while the maximum deflection of $62 \mathrm{~mm}$ was in beam B8SCW at a load of $212 \mathrm{kN}$.

\section{b) Beam horizontal-displacement}

Figure 5 and 6 show the horizontal displacement of the tested beams without and with stiffeners, respectively. In most of the test beams, with and without stiffener, the horizontal upper displacement was higher than the horizontal lower displacement. In few cases, the horizontal lower displacement at the maximum load was not observed. Moreover, the horizontal and vertical displacements were higher for the beams with stiffener than for the companion beams without stiffeners.
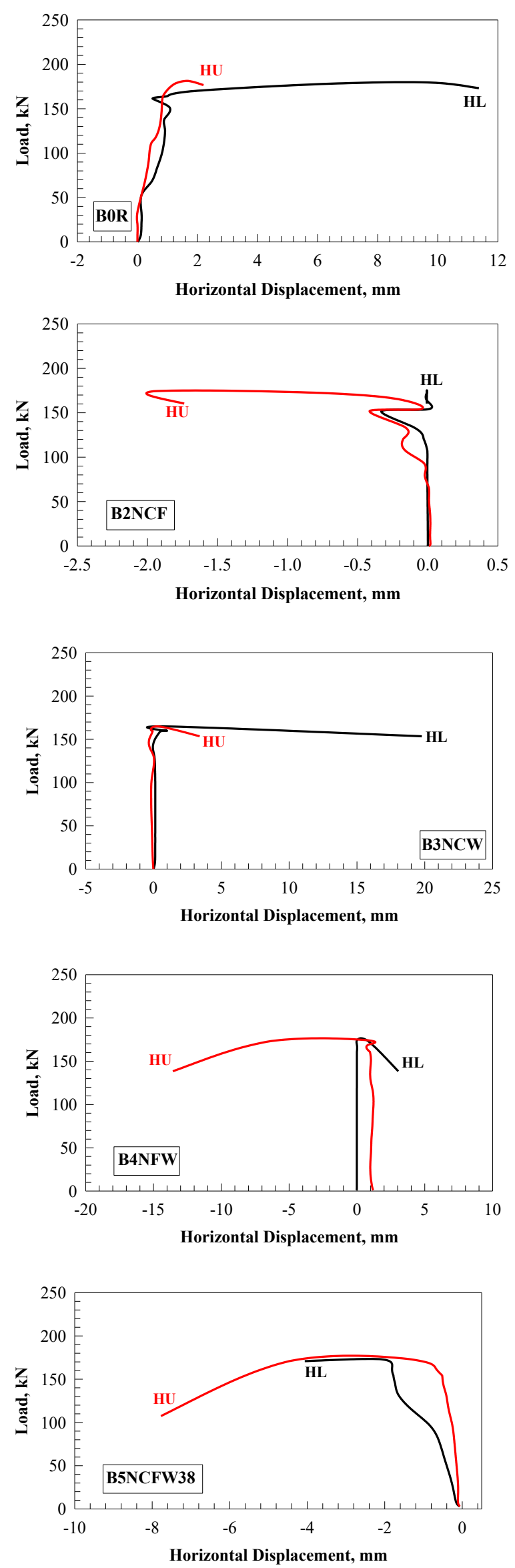

Fig. 5 The load-horizontal displacement curves for the beams without stiffeners. 
Khairedin M. Abdalla, Ghazi Abu-Farsakh, and Montaha Al-Shdiefat/

Journal of Engineering Science and Technology Review 12 (4) (2019) 60 - 68
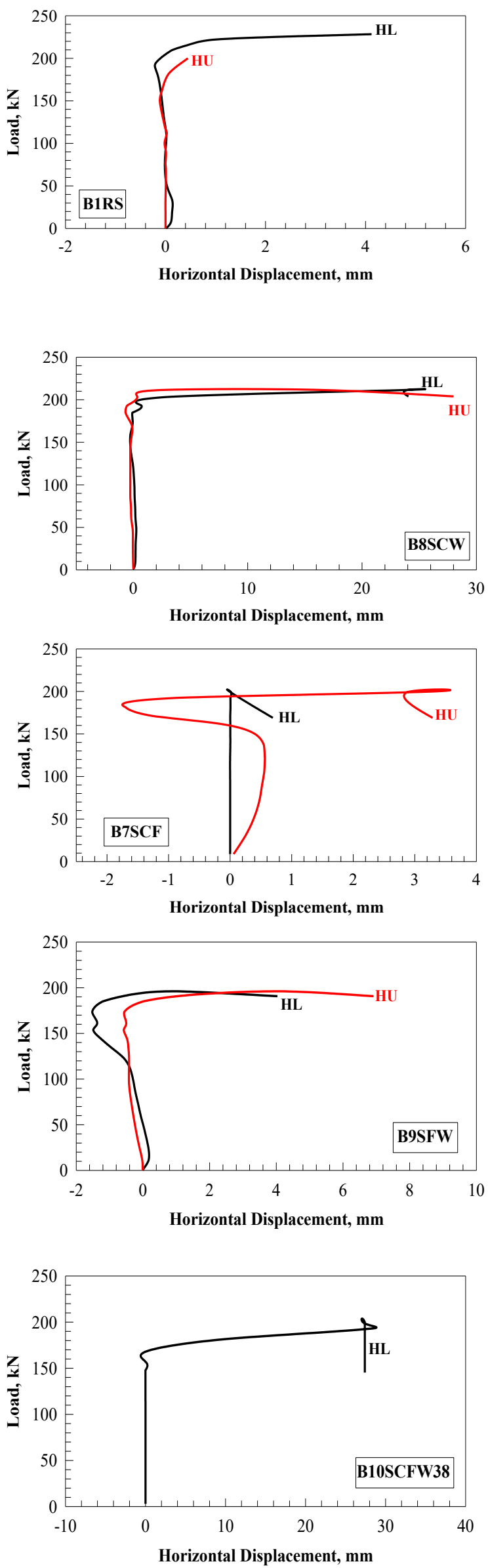

Fig. 6 The load-horizontal displacement curves for the beams with stiffener
Table 2. Beams' Section Properties

\begin{tabular}{l|l}
\hline \multicolumn{1}{c|}{ Properties } & \multicolumn{1}{c}{ Value } \\
\hline $\mathrm{A}$ & $2492.5 \mathrm{~mm}^{2}$ \\
$\overline{\mathrm{Y}}$ & $92 \mathrm{~mm}$ \\
$\overline{\mathrm{X}}$ & $45 \mathrm{~mm}$ \\
$\mathrm{I}_{\mathrm{x}}$ & $1.462 \times 10^{7} \mathrm{~mm}^{4}$ \\
$\mathrm{I}_{\mathrm{y}}$ & $1.0255 \times 10^{6} \mathrm{~mm}^{4}$ \\
$\mathrm{~S}$ & $1.589 \times 10^{5} \mathrm{~mm}^{3}$ \\
$\mathrm{Z}$ & $179629.425 \mathrm{~mm}^{3}$ \\
$\mathrm{M}_{\mathrm{y}}$ & $60.68 \mathrm{kN} \cdot \mathrm{m}$ \\
$\mathrm{M}_{\mathrm{n}}$ & $68.605 \mathrm{kN} \cdot \mathrm{m}$ \\
$\mathrm{L}_{\mathrm{p}}$ & $0.8586 \mathrm{~m}$ \\
$\mathrm{~L}_{\mathrm{b}}$ & $1.53 \mathrm{~m}$ \\
$\mathrm{~L}_{\mathrm{r}}$ & $3.51 \mathrm{~m}$ \\
Local Flange Bending & $192.881 \mathrm{kN}$ \\
Local Web Yielding & $581.644 \mathrm{kN}$ \\
Web Crippling & $461.433 \mathrm{kN}$ \\
\hline
\end{tabular}

\section{c) Strain-gages readings}

Figure 7 compares the strains of the beams without stiffener. A maximum flange strain of $35,000 \times 0^{-6}$ was observed in beam $\mathrm{B} 3 \mathrm{NCW}$, which reflects the significant impact of the use of CFRP plates on the web. The maximum web strain of $30,000 \times 0^{-6}$ was observed in beam $\mathrm{B} 2 \mathrm{NCF}$, which reflects the considerable impact of the use of CFRP plates on the flanges. The use of CFRP plates a distance of $38 \mathrm{~cm}$ from the face of support on the two web-faces had a moderate effect on the web strain of $20,000 \times 0^{-6}$ and on the flange strain of $15,000 \times 0^{-}$ ${ }^{6}$. Finally, the use of CFRP plates on the web and flanges in the middle of the beam had notable impact on the flange strain of $30,000 \times 0^{-6}$ and little impact on the web strain of $3,500 \times 0^{-6}$ Figure 8 shows that the beams with stiffeners showed higher strains in the flange and web than the companion beams without stiffener. A maximum flange strain of $30,000 \mathrm{x} 0^{-6}$ was reported in beam $\mathrm{B} 8 \mathrm{SCW}$. The maximum web strain of $35,000 \times 0^{-6}$ was observed in beam (B9SFW). The use of stiffeners and CFRP plates at a distance of $38 \mathrm{~cm}$ from the face of support on the two web-faces had a moderate effect on the web strain of $30,000 \times 0^{-6}$ and on the flange strain of $10,000 \times 0^{-6}$. Finally, the use of stiffeners and CFRP plates on the web and flanges had notable impact on the flange and web strains of $30,000 \times 0^{-6}$.

\section{d) Beam twist-angle}

Figure 9 compares the angle of twist between the beams. It was noticed that the angle of twist for most of the tested beams was less than that of the control beam $(0.0447$ at a load of $179.8 \mathrm{kN})$. Only in the case of B4NFW was the angle of twist $(0.0403$ at a load of $173.3 \mathrm{kN})$ very close to that observed in the control beam.

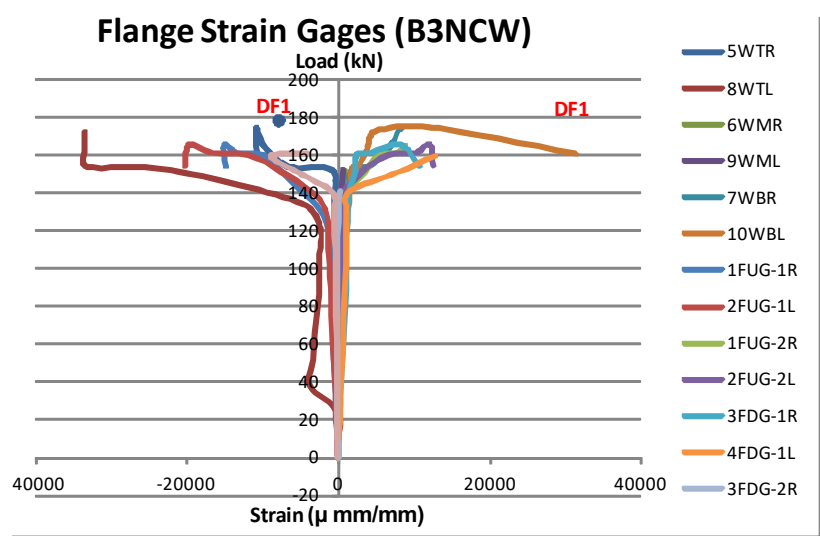


Khairedin M. Abdalla, Ghazi Abu-Farsakh, and Montaha Al-Shdiefat/

Journal of Engineering Science and Technology Review 12 (4) (2019) 60 - 68

Web Strain Gages (B3NCW)

Load (kN)
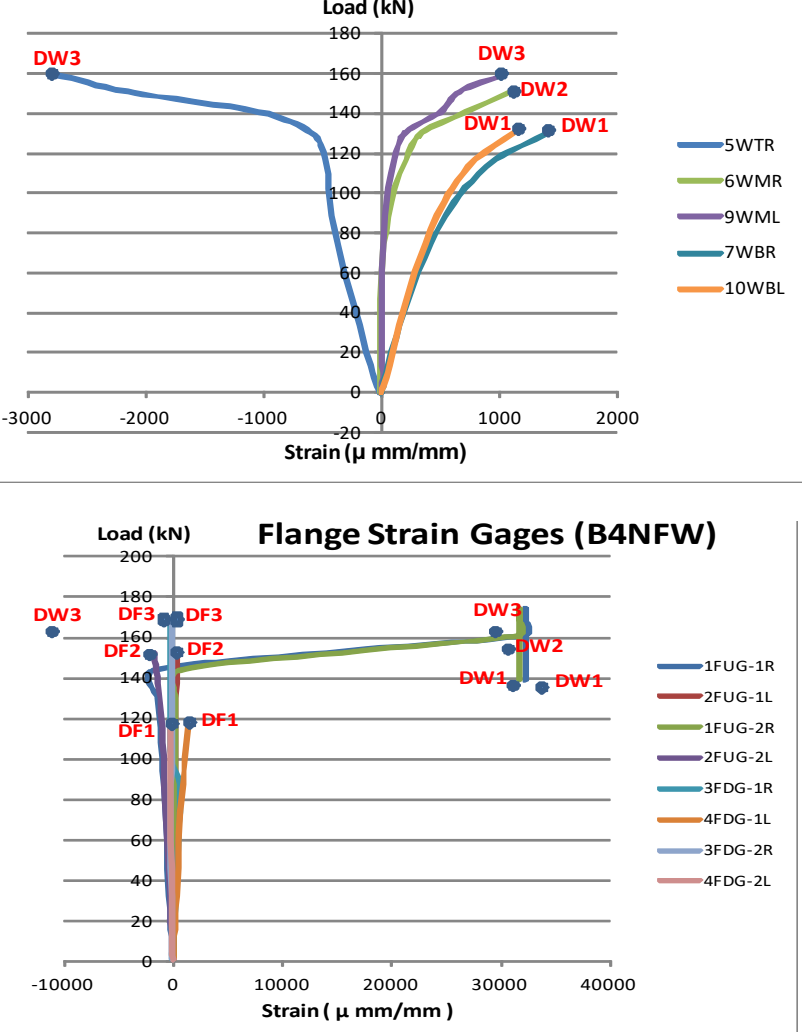

Web Strain Gages (B4NFW)

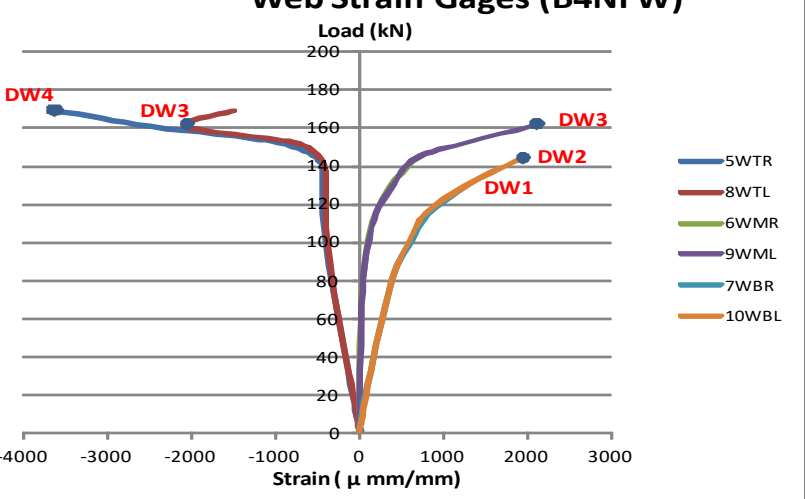

Flange Strain Gages (B5NCFW38)

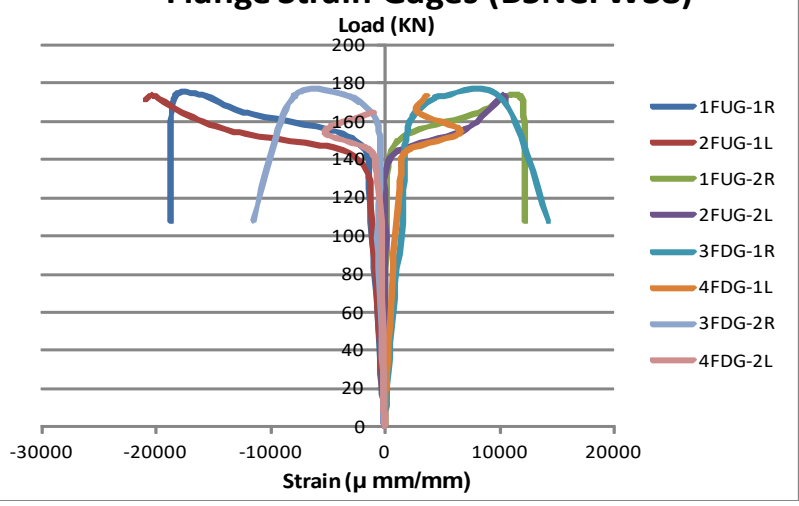

Web Strain Gages (B5NCFW38)

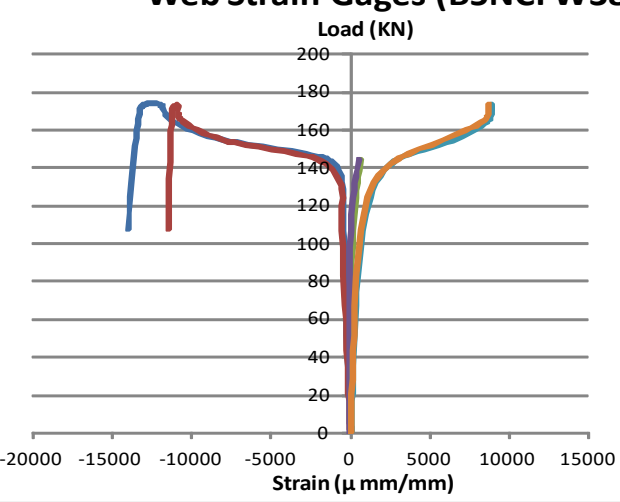

Fig. 7 The load-strains for the beams without stiffener
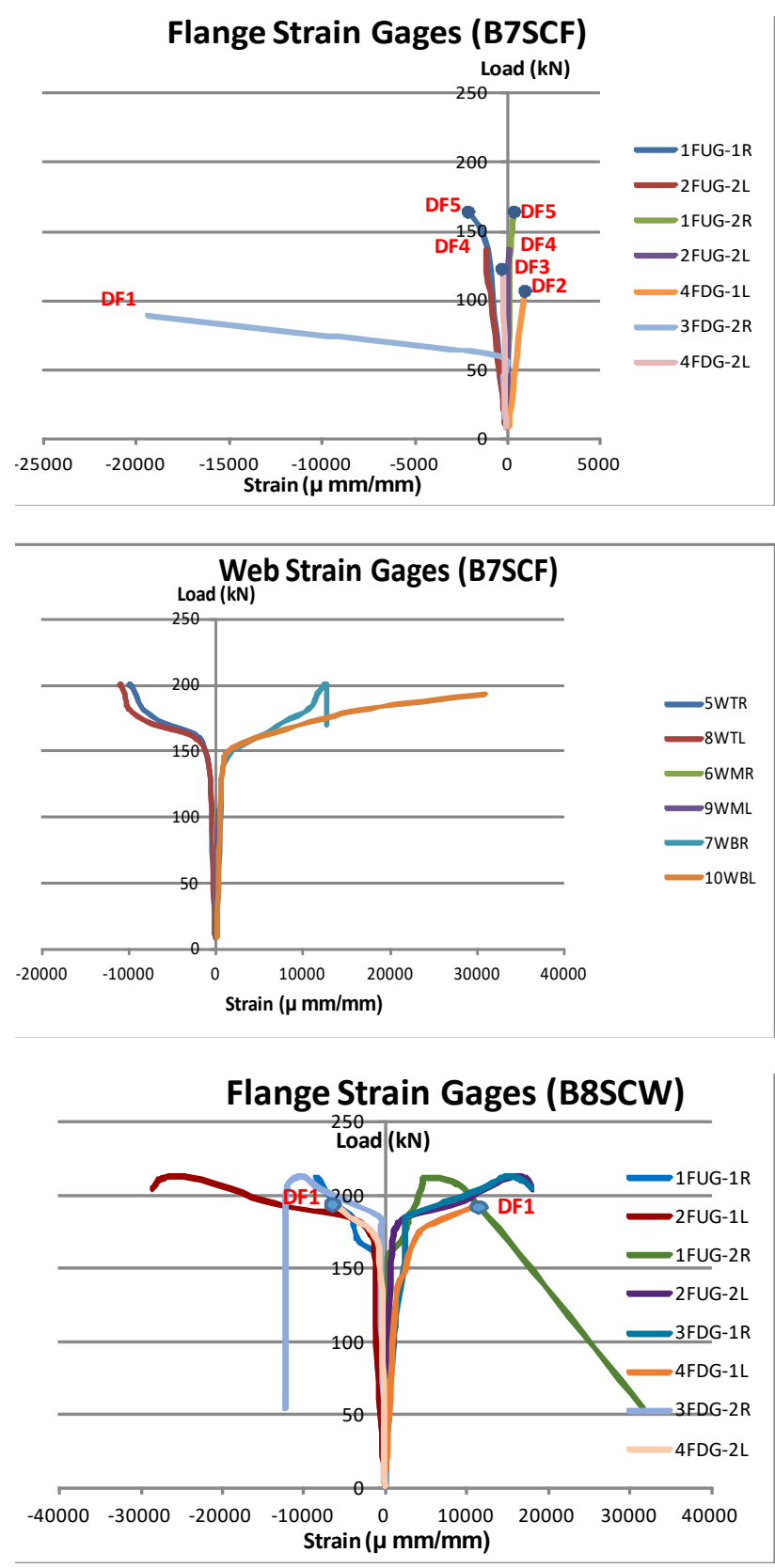
Khairedin M. Abdalla, Ghazi Abu-Farsakh, and Montaha Al-Shdiefat/

Journal of Engineering Science and Technology Review 12 (4) (2019) 60 - 68
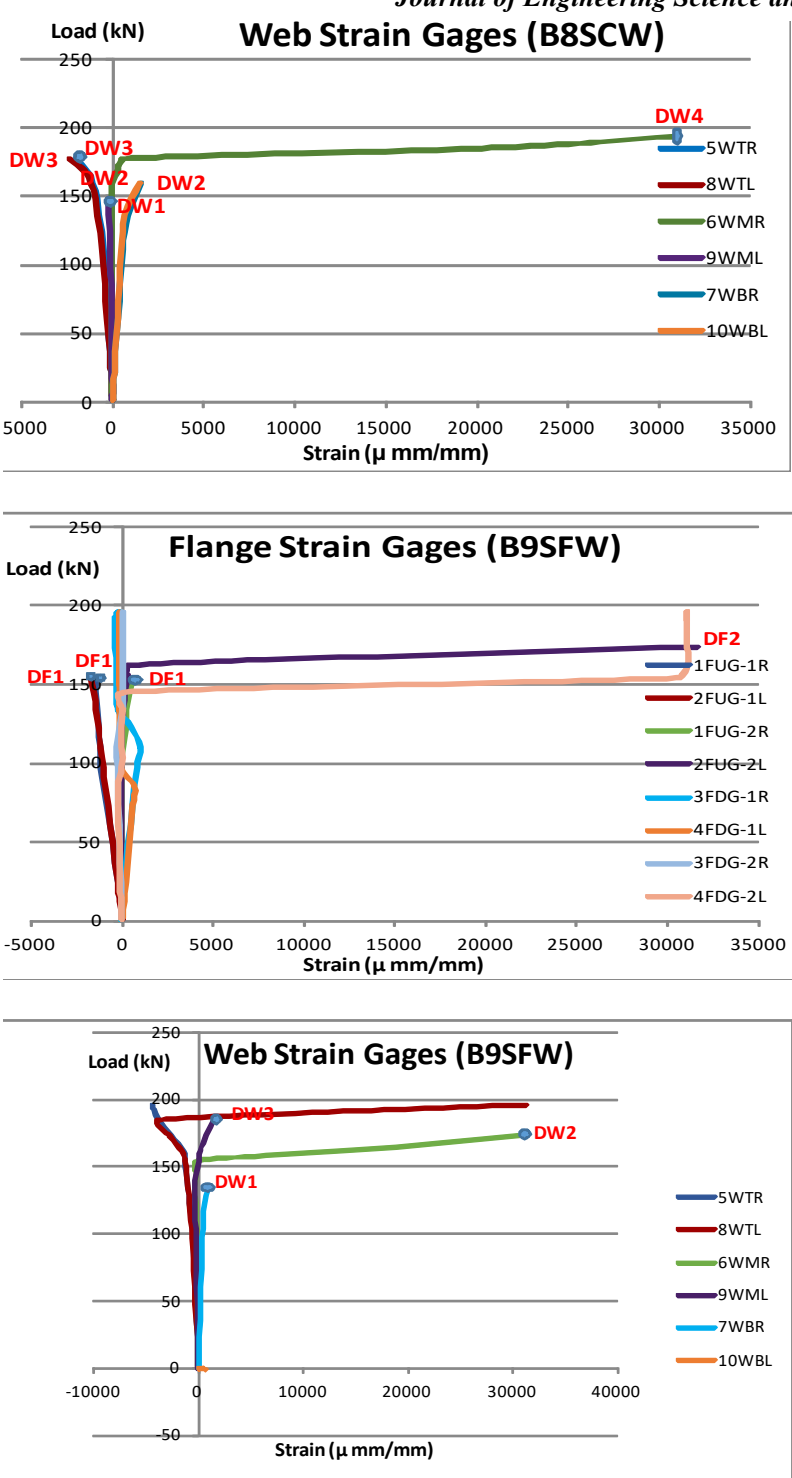

Flange Strain Gages (B10SCFW38)
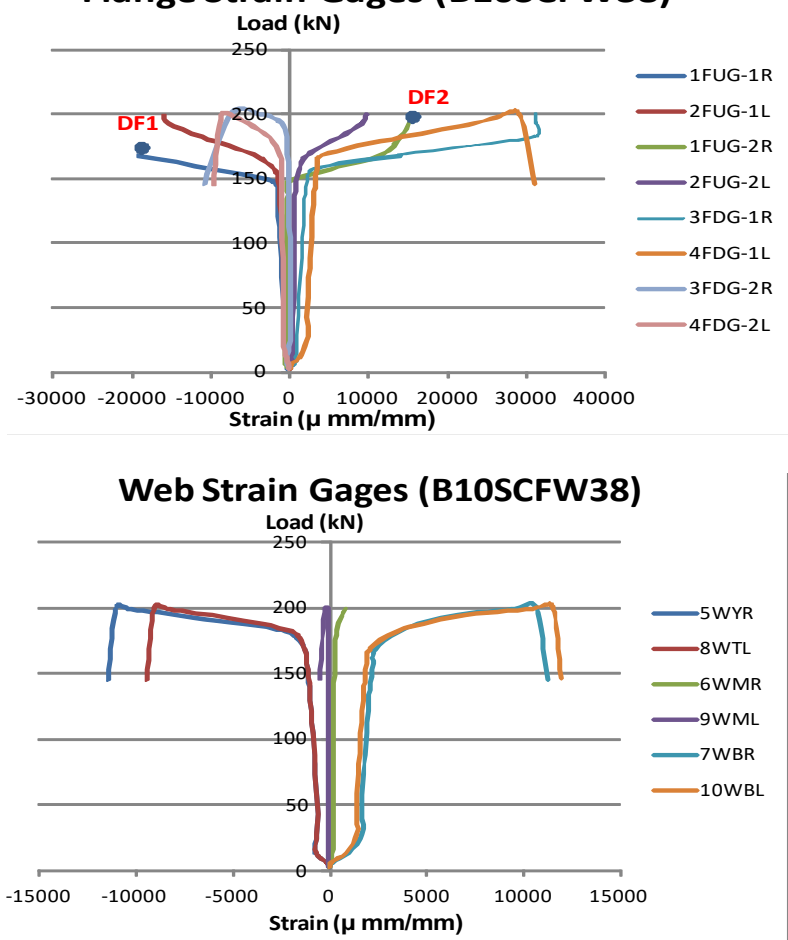

Fig. 8 The load displacement for strain gages of beams with stiffener
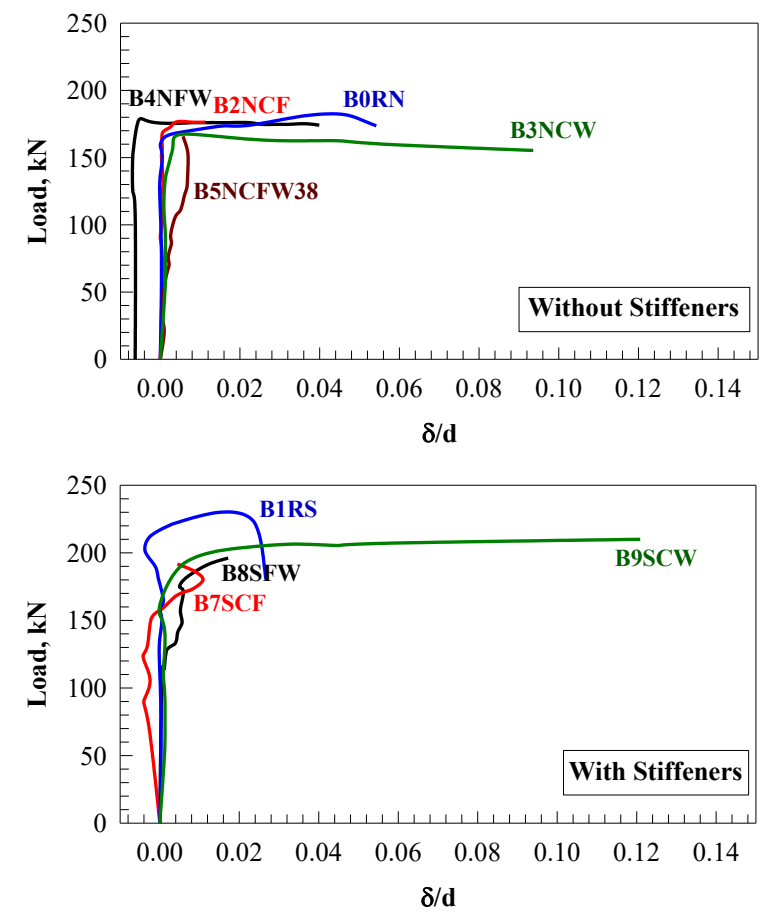

Fig. 9 Comparison in angle of twist between beams with and without stiffeners

The angles of twist of the other beams followed the descending order of B5NCFW38 (- 0.0062), B3NCW (0.0041), and B2NCF (- 0.0110). The loads affecting the latter twisting were $164.4 \mathrm{kN}, 164.8 \mathrm{kN}$, and $174.2 \mathrm{kN}$, respectively. On the other hand, the twisting induced by the applied loads was in general limited and twisting of the beams without stiffeners took place at slightly lower loads than that of beams with stiffeners. Also, Figure 9 shows that the angle of twist was the lowest for the control beam $(\sim 0.0086$ at a load of $227.9 \mathrm{kN})$. The second lowest angle of twist characterized the beam B7SCF $(\sim 0.0047$ at the load of $192.5 \mathrm{kN})$. The beam B9SFW had a much higher angle of twist $(0.0177$ at a load of $196.1 \mathrm{kN}$ ) whereas beam B8SCW had the highest angle of twist (0.1198 at a load of $211.2 \mathrm{kN})$.

\section{e) CFRP-debonding}

As summarized in Table 3, debonding of the CFRP plates occurred in many places in the beams, which passively affected the steel beam strengthening with CFRP plates. For example, in beam B2NCF all CFRP plates debonded from all areas on which the plates were placed (1FFUH, 2FBUH, 3FFUV, 4FBUV, 5FFDH, 6FBDH, 7FFDV, and 8FBDV). As such, these beams interacted to the applied load much as if they were separate, non-strengthened steel beams at higher loads than $153.74 \mathrm{kN}$. In another example, the CFRP plates debonded in web from all places (9WFU, 11WFM, 12WBM, 13WFD, and 14WBD), except 10WBU, on beam B3NCW at loads higher than $160.55 \mathrm{kN}$. Regarding beam B4NFW, Table 3 points out that the CFRP plates debonded in flange from 6 of the 8 locations on which they were placed (2FBUH, 4FBUV, 5FFDH, 6FBDH, 7FFDV, and 8FBDV). No CFRP plate debonding in flange was observed in the beams 1FFUH and 3FFUV. On the other hand, the CFRP plates debonded from web of beam B4NFW at five points: 9WFU, 10WBU, 12WBM, 13WFD, 14WB (Table 3). No CFRP plate debonding was reported by $11 \mathrm{WFM}$. 
Khairedin M. Abdalla, Ghazi Abu-Farsakh, and Montaha Al-Shdiefat/

Journal of Engineering Science and Technology Review 12 (4) (2019) 60 - 68

The results summarized in Table 4 disclose that: for B7SCF, debonding was only observed in flange, for B8SCW, debonding was only noticed in web, and for B9SFW, debonding took place both in web and flange. The results (Table 4) underline that the CFRP plates debonded in flange at seven points on beam B7SCF: 1FFUH, 2FBUH, 3FFUV, 4FBUV, 6FBDH, 7FFDV, and 8FBDV. The loads bringing these debonding incidences ranged from $89.4 \mathrm{kN}$ to $136.7 \mathrm{kN}$ (Table 4). Regarding B8SCW, debonding took place in the web only. The results (Table 4) spotlight that the CFRP plates debonded in web from six areas on this beam: 9WFU, 10WBU, 11WFM, 12WBM, 13WFD, and 14WBD. The loads leading to these events of debonding were in the range 158.9193.3 kN (Table 4). For B9SFW, debonding occurred both in flange and in web. The study results (Table 4) show that the CFRP plates debonded in flange from four areas on this beam: $1 \mathrm{FFUH}, 2 \mathrm{FBUH}, 4 \mathrm{FBUV}$, and 5FFDH. The loads resulting in these debonding incidences fell in the range 153.9-173.2 kN. Debonding of the CFRP plates was recorded at three points: 11WFM, 12WBM, and 13WFD. The loads affecting these debonding events ranged from $134.3 \mathrm{kN}$ to $184.8 \mathrm{kN}$ (Table 4).

This study found that in the cases of beams with and without stiffeners, the applied loads affected vertical displacement, horizontal lower displacement, horizontal upper displacement, twisting, and CFRP debonding to varying degrees. The applied loads resulted in debonding of
CFRP plates from the web and flanges. Consequently, the beams suffering from CFRP plate debonding behaved much like non-strengthened beams. However, to an extent, the beams with stiffeners needed somewhat higher load to bring about CFRP plate debonding than the beams without stiffeners. The governing buckling mode for the tested beams was in-elastic lateral-torsional buckling combined with localflange buckling in most cases. Fig. 10 shows photos of the some of the tested beams after failure.

\section{Conclusions}

The indeterminate steel beams having two fixed ends required high load to cause failure. The obtained maximum loads for the strengthened beams were sufficiently higher than the loads which caused CFRP-plate debonding. Therefore, no improvement was noticed in the strength of the strengthenedbeams at flanges and/or webs. Stiffness of the strengthenedbeams showed reasonable improvement concerning their flexural-stiffness as obtained from the load-vertical displacement behavior. The resulted total vertical-deflection of such beams was decreased and hence, showed relatively stiffer behavior than the corresponding un-strengthened beams. The torsional-stiffness was relatively increased for the strengthened-beams, especially, steel beams with strengthened flange and/or web. The governing buckling mode for the tested beams was in-elastic lateral-torsional buckling combined with local-flange buckling in most cases.

Table 3. Load at which Deboning of the CFRP Plates Occurred in the Unstiffened Beams

\begin{tabular}{|c|c|c|c|}
\hline & B2NCF (Load) & B3NCW (Load) & B4NFW (Load) \\
\hline 1 FFUH & DF2 $(153.7 \mathrm{kN})$ & & \\
\hline 2FBUH & DF2 ( $153.7 \mathrm{kN})$ & & DF2 $(152.3 \mathrm{kN})$ \\
\hline 3FFUV & DF2 ( $153.7 \mathrm{kN})$ & & \\
\hline 4FBUV & $\mathrm{DF} 2(153.7 \mathrm{kN})$ & & DF2 $(152.3 \mathrm{kN})$ \\
\hline $5 \mathrm{FFDH}$ & $\mathrm{DF} 1(93.1 \mathrm{kN})$ & & DF3 $(169 \mathrm{kN})$ \\
\hline $6 \mathrm{FBDH}$ & DF1 $(93.1 \mathrm{kN})$ & & DF1 (115.1 kN) \\
\hline 7FFDV & DF1 $(93.1 \mathrm{kN})$ & & DF3 $(169 \mathrm{kN})$ \\
\hline 8 FBDV & DF1 $(93.1 \mathrm{kN})$ & & DF1 $(115.1 \mathrm{kN})$ \\
\hline $9 \mathrm{WFU}$ & & DW3 (160.6 kN) & DW4 $(169 \mathrm{kN})$ \\
\hline $10 \mathrm{WBU}$ & & & DW3 $(160.8 \mathrm{kN})$ \\
\hline $11 \mathrm{WFM}$ & & DW2 (150.7 kN) & \\
\hline $12 \mathrm{WBM}$ & & DW3 $(160.6 \mathrm{kN})$ & DW3 $(160.8 \mathrm{kN})$ \\
\hline $13 \mathrm{WFD}$ & & DW1 $(130.2 \mathrm{kN})$ & DW1 $(129.8 \mathrm{kN})$ \\
\hline 14WBD & & DW1 $(130.2 \mathrm{kN})$ & DW2 $(143.5 \mathrm{kN})$ \\
\hline
\end{tabular}

Table 4. Load at which Deboning of the CFRP Plates Occurred in the Stiffened Beams

\begin{tabular}{|c|c|c|c|}
\hline & B7SCF (Load) & B8SCW (Load) & B9SFW (Load) \\
\hline 1FFUH & DF5 $(161.8 \mathrm{kN})$ & & DF1 (153.9 kN) \\
\hline $2 \mathrm{FBUH}$ & DF4 $(136.7 \mathrm{kN})$ & & $\mathrm{DF} 1(153.9 \mathrm{kN})$ \\
\hline 3FFUV & DF5 $(161.8 \mathrm{kN})$ & & \\
\hline 4FBUV & DF4 (136.7 kN) & & DF2 (173.2) \\
\hline $5 \mathrm{FFDH}$ & & & DF1 (153.9) \\
\hline $6 \mathrm{FBDH}$ & DF2 $(105 \mathrm{kN})$ & & \\
\hline 7FFDV & DF1 $(89.4 \mathrm{kN})$ & & \\
\hline 8FBDV & $\mathrm{DF} 3(120.8 \mathrm{kN})$ & & \\
\hline 9WFU & & DW3 (176.8 kN) & \\
\hline $10 \mathrm{WBU}$ & & DW3 (176.8 kN) & \\
\hline $11 \mathrm{WFM}$ & & DW4 (193.3 kN) & DW2 $(173.2 \mathrm{kN})$ \\
\hline 12WBM & & DW1 (147.8 kN) & DW3 $(184.8 \mathrm{kN})$ \\
\hline 13WFD & & DW2 (158.9 kN) & DW1 $(134.4 \mathrm{kN})$ \\
\hline 14WBD & & DW2 (158.9 kN) & \\
\hline
\end{tabular}


Khairedin M. Abdalla, Ghazi Abu-Farsakh, and Montaha Al-Shdiefat/

Journal of Engineering Science and Technology Review 12 (4) (2019) 60 - 68

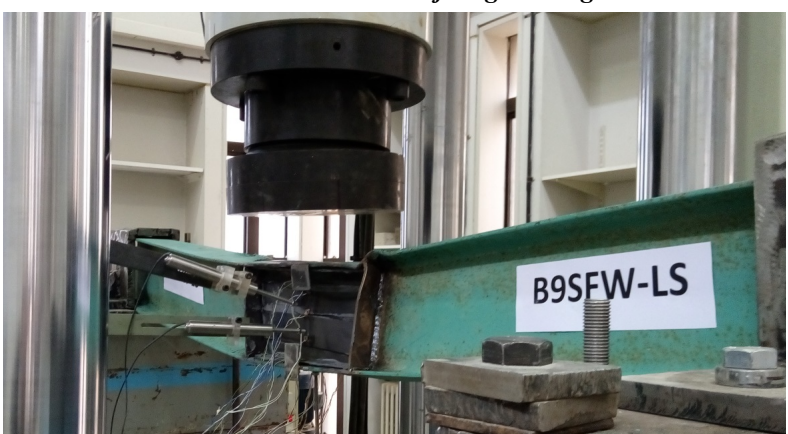

Fig. 10 Typical failure mode for observed for most specimens

\section{Acknowledgement}

This work is mainly part of the MSc thesis of the third author, which was carried out at the Civil Engineering Department, Jordan University of Science and Technology.

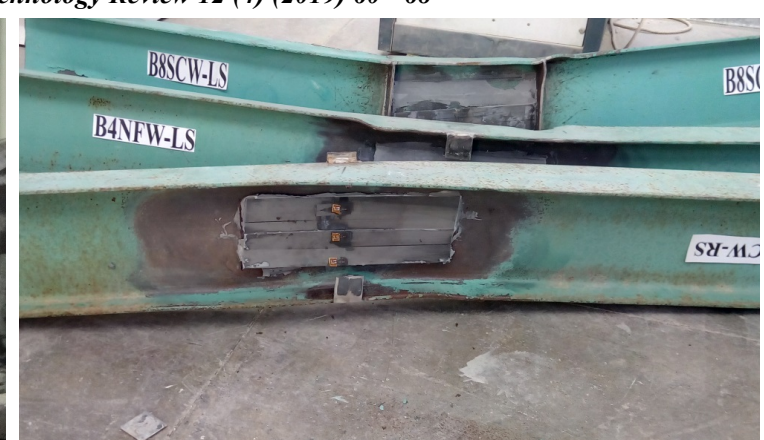

This is an Open Access article distributed under the terms of the Creative Commons Attribution License

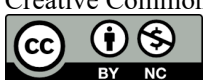

\section{References}

[1] Photiou NK, Hollaway LC, Chryssanthopoulos MK. Strengthening of Artificially Degraded Steel Beam Utilizing Carbon/Glass Composite System. Construction and Building Materials2006; 20(12):11-21.

[2] Bambach M and Elchalakani M. Plastic Mechanism Analysis of Stub columns Strengthened with CFRP under Large Axial Deformation. Thin-Walled Structures 2007; 45(2):159-70.

[3] Sahan Jayasuriya, Amirreza Bastani, Sara Kenno, Tirupati Bolisetti, Sreekanta Das. Rehabilitation of Corroded Steel Beams Using BFRP Fabric. Structures 2018; 15(1): 152-161.

[4] Sivaganesh Selvaraj, Mahendrakumar Madhavan. CFRP strengthened steel beams: Improvement in failure modes and performance analysis. Structures 2017; 12(1): 120-131.

[5] Khattab Saleem Abdul-Razzaq, Mais Malallah Abdul-Kareem. Innovative use of steel plates to strengthen flange openings in reinforced concrete T-beams. Structures 2018; 16(1): 269-287.

[6] Amirreza Bastani, Sreekanta Das, David Lawn. Rehabilitation of Shear Deficient Steel Beams Using BFRP Fabric. Structures 2019; 19(1): 349-361.

[7] Tohid Mousavi, Erfan Shafei. Impact response of hybrid FRP-steel reinforced concrete slabs. Structures 2019; 19(1): 436-448.

[8] Salama T and Abd-El-Meguid A. Strengthening Steel Bridge Girders Using CFRP. University Transportation Center for Alabama (UTCA) Report Number 06217, UTCA Theme: Management and Safety of Transportation Systems. The University of Alabama at Birmingham and the University of Alabama in Huntsville, June 2010.

[9] Teng JG, Yu T and Fernando D. Strengthening of steel structures with fiber reinforced polymer composites. Journal of Constructional Steel Research 2012; 78; 31-143.

[10]Elchalakani M. CFRP Strengthening and Rehabilitation of Degraded Steel Welded RHS Beams under Combined Bending and Bearing. Thin-Walled Structure 2014; 77, 86 -108.

[11]Batuwitage C, Fawzia S, Liu X, Thambiratnam D. and Alam MI. Bond Characteristics of Strengthened and Retrofitted Steel by Smart CFRP Technique. In Proceedings of the Second International Conference on Performance-Based and Life-Cycle Structural Engineering (PLSE 2015), 2015, Brisbane, Australia, 190-198.
[12] Narmashiri K, Sulong N H R and Jumaat MZ. Flexural strengthening of steel I-beams by using CFRP Strips. International Journal of the Physical Sciences 2011; 6(7):1620-1627.

[13] Narmashiri K, Sulong N H R and Jumaat MZ. Failure analysis and structural behavior of CFRP strengthened steel I-beams. Construction and Building Materials 2012;30, 1-9.

[14] Galal K, Seif El-Din HM and Tirca L. Flexural Performance of Steel Girders Retrofitted Using CFRP Materials. Journal of Composites for Construction 2012; 16(3):265-276.

[15]Dawood M and Rizkalla S. Bond and Splice Behavior of High Modulus CFRP Materials Bonded to Steel Structures. Third International Conference on FRP Composites in Civil Engineering (CICE 2006), December 13-15 2006, Miami, Florida, USA, 1-4.

[16]Patnaik AK, Bauer CL and Srivatsan TS. The extrinsic influence of carbon fiber reinforced plastic laminates to strengthen steel structures. Sadhana 2008; 33(3):261-272.

[17] Peiris NA. Steel Beams Strengthened with Ultra High Modulus CFRP Laminates. Unpublished Ph.D. dissertation, University of Kentucky, The USA, 2011.

[18] Koller RE, Stoecklin I, Valet S and Terrasi G. CFRP-Strengthening and Long-Term Performance of Fatigue Critical Welds of a Steel Box Girder. Polymers 2014; 6(2):443-463.

[19] Jagtap PR, Pore SM and Prakash V. Necessity of Strengthening of Steel Structures with FRP Composites: A Review. International Journal of Latest Trends in Engineering and Technology (IJLTET), 2015; 5(4):390-394.

[20]Jun Deng, Yonghui Jia, Hengzhong Zheng. Theoretical and experimental study on notched steel beams strengthened with CFRP plate. Composite Structures, 2016; 136, 450-459

[21]Junhui Li, Yi Wang, Jun Deng, Yonghui Jia. Experimental study on the flexural behaviour of notched steel beams strengthened by prestressed CFRP plate with an end plate anchorage system. Engineering Structures 2018; 171, 29-39.

[22] Mohammed J. Altaeeab, Lee S. Cunninghama, Martin Gilliec. Experimental investigation of CFRP-strengthened steel beams with web openings. Journal of Construction Steel Research 2017; 138, 750-760.

[23] Omar H. Elkhabeery, Sherif S.Safar, Sherif A.Mouradb. Flexural strength of steel I-beams reinforced with CFRP sheets at tension 